\title{
Evaluar la evaluación: aportes para una reflexión
}

\author{
Redonder, Nidia S. ${ }^{1}$; Gordo, Norma A. ${ }^{2}$
}

\section{Resumen}

Si bien mucho se pregona sobre el cómo, por qué, y para qué de los actos evaluativos, resulta particularmente más complicado llegar al consenso cuando es la misma evaluación la que es "evaluada". Se describen aquí las prácticas evaluativas desarrolladas en tres facultades de la UNL con respecto a la disciplina Idioma Extranjero, señalando similitudes y diferencias, ventajas y desventajas de las metodologías y enfoques adoptados. Se apunta a trascender los límites descriptivos de la realidad en un espacio de reflexión y discusión basado esencialmente en la revisión a conciencia de los resultados de cada enfoque y/o metodología, para poder concretar una verdadera autoevaluación del docente que dé cuenta de la responsabilidad de su misión.

\footnotetext{
${ }^{1}$ Cátedra de Inglés Técnico. Facultad de Ingeniería y Ciencias Hídricas y Facultad de Bioquímica y Ciencias Biológicas (UNL)

2 Área Idiomas. Facultad de Ingeniería Química y Cátedra de Inglés Técnico. Facultad de Bioquímica y Ciencias Biológicas (UNL)
} 